\title{
Estructuras de poder en el control de los medios televisivos privados de América andina
}

\section{Structures of power in the control of the private television media of Andean America}

\author{
Orlando E. Valdez-López; Luis M. Romero-Rodríguez; Ángel Hernando-Gómez
}

Cómo citar este artículo:

Valdez-López, Orlando E.; Romero-Rodríguez, Luis M., Hernando-Gómez, Ángel (2019). "Estructuras de poder en el control de los medios televisivos privados de América andina". El profesional de la información, v. 28, n. 6, e280605.

https://doi.org/10.3145/epi.2019.nov.05

Artículo recibido el 24-03-2019

Aceptación definitiva: 02-10-2019

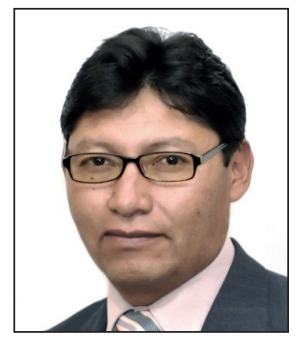

Orlando E. Valdez-López $ه$ https://orcid.org/0000-0001-6038-7313

Universidad Técnica de Oruro Ciencias de la Comunicación Social Av. 6 de octubre entre Ayacucho y Cochabamba, Oruro, Bolivia valdezlopezorlando@hotmail.com

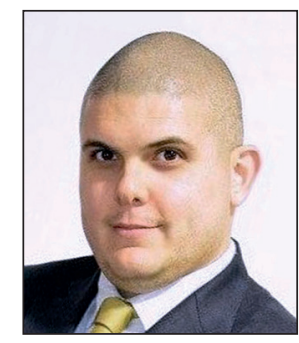

Luis M. Romero-Rodríguez https://orcid.org/0000-0003-3924-1517

Universidad Espíritu Santo ESAI Business School, Ecuador Universidad Rey Juan Carlos Camino del Molino, s/n. 28943 Fuenlabrada (Madrid), España luis@romero-rodriguez.com

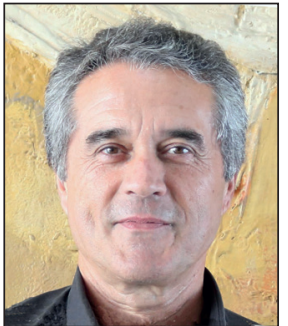

\section{Ángel Hernando-Gómez} https://orcid.org/0000-0002-6414-5415

Universidad de Huelva Departamento de Psicología Social, Evolutiva y de la Educación Campus de El Carmen. Av. de las Fuerzas Armadas, s/n. 21007 Huelva, España angel.hernando@dpsi.uhu.es

\section{Resumen}

Se analiza y describe la configuración de las estructuras mediáticas de quienes controlan los medios televisivos de cobertura nacional en la América andina: Argentina, Bolivia, Colombia, Chile, Ecuador y Perú. A través de una revisión crítica de documentos, se pone de manifiesto que existen personas, grupos familiares, conglomerados empresariales nacionales y transnacionales de múltiples actividades, que tienen vínculos en varios casos con los políticos y gobiernos de turno, quienes constituyen las estructuras del poder mediático que dominan los contenidos de infoentretenimiento y la opinión pública; la economía y el mercado, el adoctrinamiento ideológico y la política gubernamental en los países de la región andina.

\section{Palabras clave}

Televisión privada; Estructuras de poder; Empresas transnacionales; Conglomerados mediáticos; Economía; Política; Gobierno; Contenidos televisivos; Opinión pública; Control mediático; Grupos de poder; Medios; Televisión; América Latina.

\section{Financiación}

Este trabajo se ha elaborado en el marco de Alfamed (Red Euroamericana de Investigadores), con el apoyo del Proyecto I+D+I "YouTubers e instagrammers: la competencia mediática en los prosumidores emergentes" (RTI2018093303-B-100) financiado por la Agencia Estatal de Investigación del Ministerio de Ciencia, Innovación y Universidades de España y el Fondo Europeo de Desarrollo Regional (Feder). 


\begin{abstract}
This article analyzes and describes the configuration of the media structures of those who control television media with national coverage in Andean America: Argentina, Bolivia, Colombia, Chile, Ecuador and Peru. Through a critical review of documents, it becomes clear that there are people, family groups, national and transnational business conglomerates of multiple activities, which have links in several cases with the politicians and governments in power, who constitute the structures of power, that dominate the content of infotainment and the public opinion; the economy and the market; ideological indoctrination and the government policy in the countries of the Andean region.
\end{abstract}

\title{
Keywords
}

Private television; Power structures; Transnational companies; Media conglomerates; Economy; Politics; Government; Television content; Public opinion; Media control; Power groups; Media; TV; Television chains; Latin America.

\section{Introducción}

En los países latinoamericanos los canales de televisión emergieron fundamentalmente por la acción de sus gobiernos. Cuando creció el espectro y se incrementaron las audiencias se conformaron empresas privadas y se licitaron licencias de transmisión. En varias regiones se adoptó el modelo televisivo de Estados Unidos, en cuanto a programación y producción de contenidos, salvo en Colombia y Chile, que adoptaron características de

Una nueva forma de control y retención del poder gubernamental es: comprando medios privados a través de personas jurídicas afines al gobierno, para manejar de forma totalitaria la línea editorial del régimen televisión pública y universitaria, aunque al final terminaron constituyéndose como instrumentos estatales y privados, repetidores de contenidos y formatos de producción extranjera (Martín-Barbero, 2005). En realidad, en todo el mundo el modelo y mercado de Estados Unidos tiene supremacía, su renta per cápita es elevada, exporta contenidos a precio reducido y tiene un amplio catálogo (Delgado; Prado; Navarro, 2017).

Los medios televisivos privados se han concentrado en consorcios familiares y conglomerados de grupos de élite económica que tienen vínculos con el poder político. Se distinguen distintos factores de negociación por el poder mediático/ político. En este trabajo se analizan documentos sobre la situación mediática televisiva, donde la concentración de grupos de medios privados-comerciales ostentan desde hace varias décadas el control mediático (De-Charras; Lozano, 2017). Según Toussaint (2017)

"en la década de 1950 -fecha de comienzo de las primeras emisiones televisivas latinoamericanas- el esquema primigenio sufrió la influencia determinante del modelo comercial de Estados Unidos [...]. No hay economía de la región que no adopte las políticas imperiales, especialmente en materia de telecomunicaciones" (pp. 226-227).

La realidad del control de los medios televisivos en Latinoamérica es compleja por las posturas ideológicas marcadas por el poder político gubernamental y el poder económico empresarial. Este hecho ha cambiado frecuentemente el panorama mediático en desmedro de la televisión pública, donde han prevalecido los intereses particulares en el ejercicio del poder mediático concebido por el flujo económico, como indica con solvencia Ramón Reig, pues la tarea comunicacional ha sido absorbida por la nueva economía global [...]

"las grandes (y no tan grandes) empresas mediáticas, ya de por sí complejas, a su vez no son más que piezas de un rompecabezas macro-estructural llamado Mercado" (Reig, 2010, p. 89).

Gerber, Mastrini y Brant (2017) explicitan y justifican que la posición ideológica de los gobiernos de "izquierda" han favorecido la consolidación del ecosistema comunicacional con visión popular y en contra de la profusión de los medios privados, defendiendo que la regulación mediática debe ser una tarea inmediata y permanente. En este sentido, refieren que $[\ldots]$

"asumir estas cuestiones le permitirá a la izquierda salir del laberinto en que se encuentra en relación a los grandes medios de comunicación de la región" (p. 15).

Sin embargo, esta situación resulta debatible por la función propagandística que cumplen en la sociedad los medios estatales afines al oficialismo en la región.

Los intereses mercantiles de las empresas privadas y las posiciones políticas de gobiernos de izquierda o de derecha gestan un escenario mediático confuso que deteriora las sociedades, un fenómeno que involucra también a la actividad periodística que se encuentra en crisis por el acoso económico y político de las estructuras poder, que activan la articulación interesada de las «6 P» (Propiedad, Política, Publicidad, Producción de la información, Públicos y Periodismo) para el control definitivo de la sociedad (Reig, 2015).

Los intereses mercantiles de las empresas privadas y las posiciones políticas de gobiernos gestan un escenario mediático confuso que deteriora las sociedades 
Bajo este panorama ¿Quiénes controlan las estructuras mediáticas televisivas en la región andina? ¿Cuál es su propósito? A través de este trabajo de revisión crítica de bibliografía y fuentes originales públicas se buscará dilucidar estas cuestiones. Se ha empleado el método de análisis comparativo documental que según Ariza y Gandini (2012) en su acepción más habitual, ha sido definido como la descripción y la explicación de las condiciones y los resultados semejantes y diferentes entre unidades sociales grandes. El método comparativo de forma operativa (Tonon, 2011) describe semejanzas y desemejanzas. En esta línea, se trabajó con el presente, siendo su despliegue horizontal y cronológico, comparación de objetos que pertenecen al mismo género y que en el criterio de uniformidad se diferencia de la mera comparación. Se efectuó una prudente selección de los casos a comparar, tarea que se desarrolló siguiendo criterios metodológicos, lo cual significa que los casos elegidos presentan variables similares consideradas como constantes y las variables disimilares como datos interesantes contrastados respectivamente. En consecuencia, en este proceso investigativo comparativo,

"incluso pueden recolectarse datos adicionales para refinar el análisis [...] en un análisis cualitativo comparativo, son agrupados y se les efectúan mediciones para ahondar en las diferencias" (Hernández; Fernández; Baptista, 2010, p. 588)

En este trabajo de análisis comparativo, se diferencia, clasifica y se revela quiénes son los "dueños de la información”, y sus propósitos en el control de las estructuras mediáticas televisivas privadas de cobertura nacional en los países andinos de América del Sur: Argentina, Bolivia, Colombia, Chile, Ecuador y Perú.

\section{Control de los medios televisivos privados en Argentina}

Desde sus inicios, la televisión argentina estuvo vinculada al beneficio de las élites económicas y políticas que constituyen la política comunicacional mediática, razón de la lógica mercantil que se sustenta en la conformación de grupos de poder mediático (Sanmartín; Avelino; Reyes; Cruz, 2017). A fines del siglo pasado, el gobierno de Carlos Menem sostuvo un período de privatización de canales estatales. La televisión privada ingresó en el escenario mediático con gran expectativa, concibiendo programas de entretenimiento (Brandy, 2014).

En la actualidad, las concentraciones y conglomerados de empresas de medios de comunicación es una característica de los grupos de economía hegemónica en el control de los medios. Uno de ellos es el grupo UNO Medios (perteneciente a las familias Vila, $95 \%$ y Manzano, 5\% de acciones), que concentra por regiones el tendido de la red de TV por cable Supercanal Holding y TV abierta con 5 canales, entre ellos LS85 Canal 2 de La Plata América TV. El grupo español internacional Prisa se extendió en todo sentido en la captación de medios, en 2016 vendió a la estadounidense Viacom el canal de televisión abierta Telefe por 345 millones de US\$ y otros ocho canales propios en el interior del país. También se incluyó en la venta Telefe Internacional, TV de pago de cobertura para América Latina con alrededor de 10 millones de suscriptores en más de una decena de países. El grupo Clarín es otro conglomerado mediático poderoso que cuenta con señales locales y nacionales, en televisión abierta la principal es LS85 Canal 13 de la Capital Federal (De-Charras; Lozano, 2017).

El control privado televisivo incide en la vida democrática de la sociedad (Trejo-Delarbre, 2010) y la dispersión de audiencias favorece al control y a los ratings nacionales altos que poseen Telefe y Canal 13. La pertenencia de los medios televisivos corresponde a los siguientes grandes grupos de conglomerados (Carenzo; Felipe, 2018):

- grupo Telefe posee canal 11,

- grupo Clarín posee canal 13,

- grupo Ávila (Carlos Ávila) es el tercer grupo en importancia y posee América TV.

Según Becerra y Mastrini la correlación de fuerzas se concreta en las alianzas económicas y favores gubernamentales que provoca la crisis global respecto de las políticas y reglas cambiantes por los últimos gobiernos. En la actualidad la autorización de licencias para los grandes grupos reduce las asimetrías y ensancha las expectativas empresariales.

“El principal beneficiado es el grupo Clarín, que vio cómo desaparecieron los límites a su expansión -con apoyo gubernamental-, se le facilitó el acceso a nuevos mercados y se reguló en forma asimétrica a los otros grandes grupos [...]. Con la fusión entre Clarín y Telecom, el grupo pasa a detentar el control operativo" (Becerra; Mastrini, 2018, p. 1).

En la figura 1 se observa el panorama de los grupos empresariales que son dueños de los medios de comunicación en Argentina.

La democratización de la comunicación definida en las constituciones políticas de los países de la región es un hecho plausible, pero no suficiente en la práctica. Su aplicación desde una perspectiva político-partidista de gobierno no es significativa, y es poco provechosa para el público. El "tira y afloja" entre el ejercicio de los poderes económico y político es permanente. Según Gerber, Mastrini y Brant (2017) el gobierno de Néstor Kirchner no introdujo grandes alteraciones 


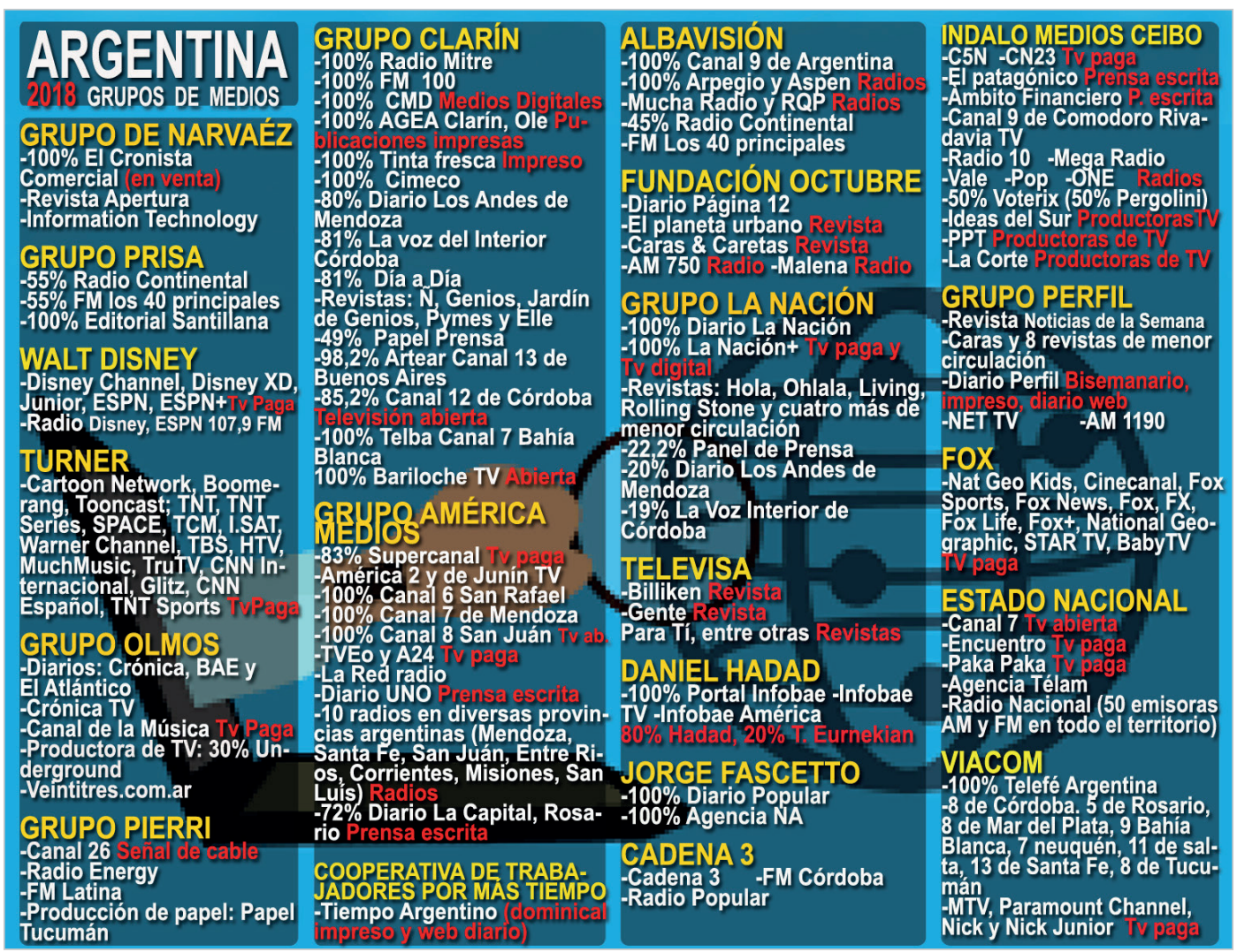

Figura 1. Dueños de los medios de comunicación en Argentina. Fuente: Elaborado a partir de Becerra y Mastrini (2018, p. 1) http://bit.ly/2CkBeUt

en la relación entre medios y poder. Los medios de comunicación continuaron con su pujante economía y coadyuvaron al gobierno, mientras que las mayores críticas vinieron de los medios vinculados a las posiciones del poder económico más concentrado, como el diario La Nación, pionero en la denuncia del populismo y la corrupción. En ese primer período, el grupo Clarín sostuvo un prudente silencio al respecto.

Tabla 1. Medios nacionales televisivos privados de Argentina

\begin{tabular}{|c|c|c|l|l|}
\hline No & Medio TV & Inicio & \multicolumn{1}{|l|}{ Función/programación } & \multicolumn{1}{c|}{ Control } \\
\hline 1 & Elnueve & 1960 & $\begin{array}{l}\text { Informar y entretener } \\
\text { (generalista) }\end{array}$ & $\begin{array}{l}\text { Albavisión (Remigio Ángel González) } \\
\text { Telearte SA }\end{array}$ \\
\hline 2 & Eltrece & 1960 & $\begin{array}{l}\text { Informar y entretener } \\
\text { (generalista) }\end{array}$ & $\begin{array}{l}\text { Grupo Clarín (Principales accionistas: Ernestina Herrera de Noble, Héctor Horacio } \\
\text { Magnetto, José Antonio Aranda, y Lucio Rafael Pagliaro) } \\
\text { Arte Radiotelevisivo Argentino SA }\end{array}$ \\
\hline 3 & Telefe & 1961 & $\begin{array}{l}\text { Informar y entretener } \\
\text { (generalista) }\end{array}$ & $\begin{array}{l}\text { Viacom EUA } \\
\text { (Presidente para América: Pierluigi Gazzolo) } \\
\text { Televisión Federal SA }\end{array}$ \\
\hline 4 & América & 1966 & $\begin{array}{l}\text { Informar y entretener } \\
\text { (generalista) }\end{array}$ & $\begin{array}{l}\text { Grupo América (Presidente: Daniel Eduardo Vila) y Claudio Belocopitt. } \\
\text { Operado por: América TV SA }\end{array}$ \\
\hline 5 & Net TV & 2018 & Entretener & $\begin{array}{l}\text { Grupo Perfil (Jorge Alberto Fontevecchia) } \\
\text { Kuarzo Entertainment Argentina }\end{array}$ \\
\hline
\end{tabular}

La articulación política con los grupos empresariales-mediáticos ha sido una constante en el control de los medios televisivos en Argentina, situación que afecta a los contenidos que se presentan sesgados, o con carga sensacionalista y banalidad, reflejados en programas como los de infoentretenimiento, que es la presentación espectacular de información de hechos generales de forma entretenida. Esta situación va en contraposición a una televisión de calidad que exige la ciudadanía.

\section{Control de los medios televisivos privados en Bolivia}

La televisión privada se creó en 1979 y como empresa comercial se propició a partir de 1984 (Toussaint, 2017). Durante este período se produjo un sistema mediático condicionado de intereses empresariales comerciales y políticos, además de la regulación y la tecnificación interna de los medios. En la década de 1990 y en el nuevo milenio se procedió a la configuración mercantil de los medios, inversión de capitales extranjeros y la conformación de grupos mediáticos. Entre 
los grupos de propietarios de medios televisivos nacionales se hallan:

- Grupo Prisa (España) dueño del canal ATB,

- familia Monasterio dueña del canal UNITEL,

- familia Kuljis de la Red UNO,

- familia Asbún (Illimani de Comunicaciones) dueña de canal 5 Bolivisión.

Tras la crisis de Estado en 2003 se empezó con la "reconformación" del sistema de medios de comunicación, con más cobertura y licencias para medios de comunidades "sociales-originarias" (Contreras-Baspineiro, 2005).

Luego de la debacle en la democracia boliviana en 2003, con la transición gubernamental de Carlos Mesa y la ascensión del gobierno de Evo Morales el año 2005, se empezó a reconfigurar el panorama mediático, en la posibilidad del control de los medios para los grupos sociales, y también la oportunidad del gobierno para el control mediático:

"Lejos de la lógica mercantil que guió la reestructuración de 1984-85 la actual reconfiguración del campo mediático está articulada por la pugna en pos del control del poder político e implica una división bipolar de dicho campo. El predominio de la iniciativa privada [...] está hoy sustituido por el de la iniciativa gubernamental" (Torrico-Villanueva, 2011, p. 259).

Los medios de comunicación nacionales influyentes que pertenecían a la empresa privada por varios años durante la actual gestión de gobierno sufrieron un cambio en el control del sistema mediático (Peñaranda, 2014). Los diarios La Razón, Extra y la teledifusora ATB (canal de alto rating) fueron parte del grupo español Prisa hasta 2009, año en el que cambiaron de dueño, se conformó una empresa desconocida de nombre Akaishi Investments con personas responsables afines al gobierno. El canal red PAT, fundado en 1990 por un grupo de periodistas, fue luego vendido al empresario Abdallah Daher en 2007, y posteriormente comprado por la Comercializadora Multimedia del Sur SRL cuyo representante legal es José Luis Valencia, empresa y personaje desconocido en el ámbito empresarial-mediático pero muy próximo al gobierno. El precitado autor remarca que las negociaciones de la compra de medios de comunicación "paraestatales" avanzaron en varias reuniones. En una de esas el director de ATB Jaime Iturri fue mediador en la negociación para la compra de PAT:

"Iturri les explicó entonces que el gobierno mantenía el interés de compra de la empresa [...] García Linera -Vicepresidente de Bolivia- entró en la suite, conversó sobre aspectos varios y luego abordó el asunto: señaló que estaba al tanto de los avances en las negociaciones" (Peñaranda, 2014, p. 41).

El autor del libro Control Remoto, Peñaranda (2014), determina la presunta injerencia gubernamental a través de la vicepresidencia en la compra y el control de los medios televisivos ATB, PAT, Full TV y el periódico La Razón, con el fin de controlar la línea editorial y la opinión pública. Álvaro García Linera niega tal participación y dice ser sólo "dueño de libros" (Erbol, 2014).

En la parte legal, la distribución de los canales de televisión a partir de 2011 con la Ley General de Telecomunicaciones, y Tecnologías de Información y Comunicación determina la "nueva repartición" de las frecuencias de medios de comunicación. En el artículo 10 señala que el 33\% corresponde a medios del Estado, 33\% para uso comercial empresarial privado, el $17 \%$ para medios comunitarios, y el otro $17 \%$ para pueblos indígenas originarios.

Al parecer esto no se cumple. Según la ministra de Comunicación de Bolivia,
Luego de la debacle en la democracia boliviana en 2003, con la transición gubernamental de Carlos Mesa y la oportunidad de la ascensión del gobierno de Evo Morales el año 2005, se empezó a reconfigurar el panorama mediático

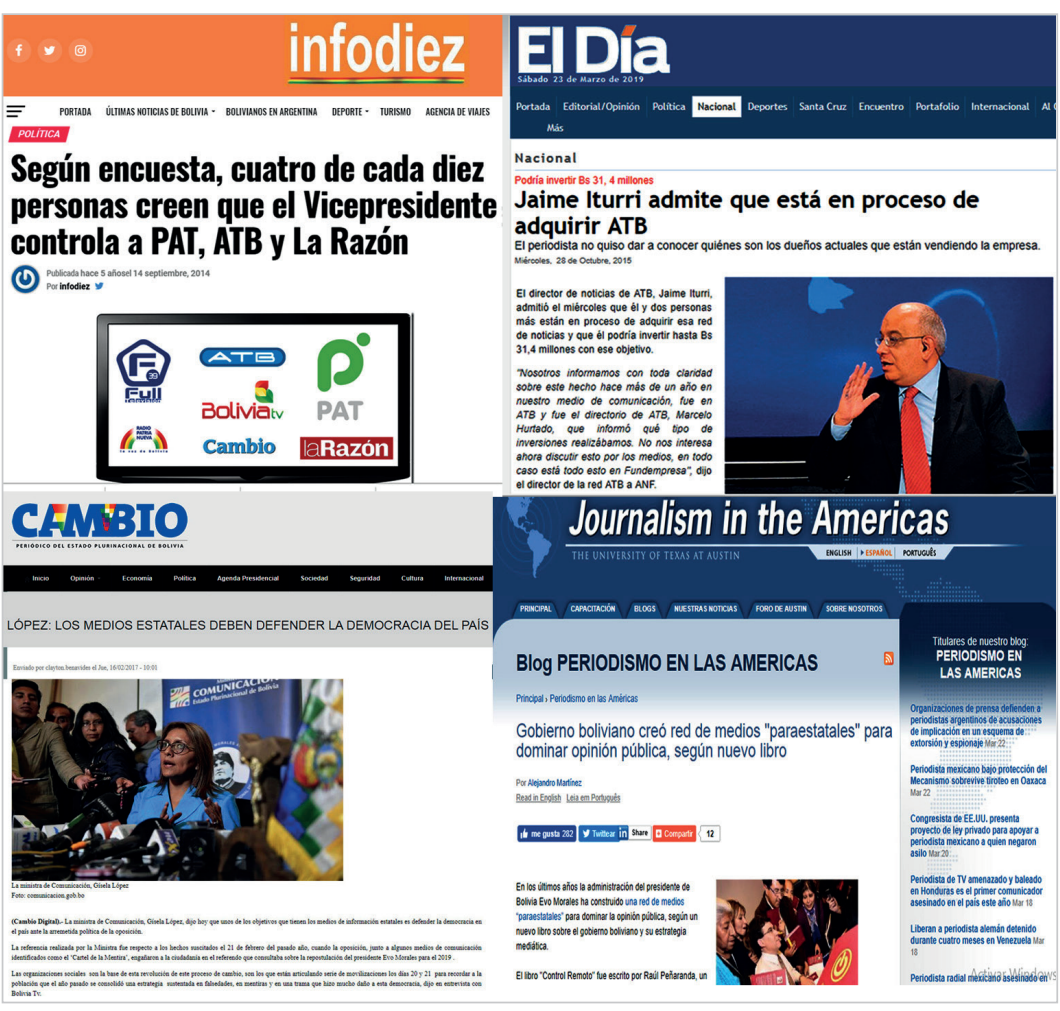

Figura 2. Publicaciones sobre los medios "paraestatales" en Bolivia. Fuente: Elaborado a partir del periódico digital Infodiez (http://bit.ly/2HN8kR8), el periódico El día (http://bit. ly/2Tt6Spl), el periódico Cambio (http://bit.ly/2OoXFNV) y Periodismo en las Américas (http:// bit.ly/2USkc8r) 
Gisela López, alrededor de un 80\% son medios de comunicación privados, un $20 \%$ no son precisamente estatales, sino son administrados por movimientos sociales, y un porcentaje mínimo pertenece al Estado: una cadena de televisión, una cadena de radio y un periódico (Ackerman, 2018), situación que confirma la presencia privada en el control de los medios.

Según la ATT-Autoridad de Regulación y Fiscalización de Telecomunicaciones y Transportes (2019) las razones sociales de las licencias de funcionamiento de los medios televisivos privados de Bolivia son las siguientes:

- Unitel, propiedad de la Empresa de Comunicaciones del Oriente Ltda.

- RTP (Radio Televisión Popular), de Radiodifusoras Populares SA

- ATB, de Illimani de Comunicaciones SA

- Red Uno, de Bolivia SA

- Cadena A, de la Compañía Comercial Minera Ricacruz Ltda.

Cabe señalar que la ATT mantiene las razones sociales prescritas para las redes PAT y Bolivisión.

En este escenario de control mediático, al gobierno de Evo Morales le incomodan las críticas de especialistas en el área de comunicación, sobre el vínculo que tendría el gobierno con algunos medios privados de alcance nacional como ATB, PAT y otros medios. El juego de intereses es notorio por el control de las estructuras del poder mediático, sean estos comerciales o políticos, por consiguiente, el control del flujo informativo interesado en incidir y manejar la opinión pública. También, se pone de manifiesto un nuevo tipo de estructura mediática de poder, compuesta por medios estatales y privados cuyos "dueños" son personas afines al régimen. El resultado es: control y poder mediático total del gobierno de turno.

Tabla 2. Medios nacionales televisivos privados de Bolivia

\begin{tabular}{|c|l|l|l|l|}
\hline No & \multicolumn{1}{|c|}{ Medio TV } & Inicio & \multicolumn{1}{c|}{ Función/programación } & \multicolumn{1}{c|}{ Control } \\
\hline 1 & Red ATB & 1984 & $\begin{array}{l}\text { Informar y entretener } \\
\text { (generalista) }\end{array}$ & $\begin{array}{l}\text { Illimani de Comunicaciones SA / } \\
\text { Akaishi Investments }\end{array}$ \\
\hline 2 & Red Uno & 1984 & $\begin{array}{l}\text { Informar y entretener } \\
\text { (generalista) }\end{array}$ & $\begin{array}{l}\text { Red Uno de Bolivia SA } \\
\text { (Grupo Kuljis) }\end{array}$ \\
\hline 3 & RTP & 1984 & $\begin{array}{l}\text { Informary entretener } \\
\text { (generalista) }\end{array}$ & Radiodifusoras Populares SA \\
\hline 4 & Unitel & 1987 & $\begin{array}{l}\text { Informar y entretener } \\
\text { (generalista) }\end{array}$ & $\begin{array}{l}\text { Empresa de Comunicaciones del Oriente Ltda. } \\
\text { (Osvaldo Monasterio Añez) }\end{array}$ \\
\hline 5 & Bolivisión & 1996 & $\begin{array}{l}\text { Informar y entretener } \\
\text { (generalista) }\end{array}$ & $\begin{array}{l}\text { Albavisión } \\
\text { (Remigio Ángel González) } \\
\text { Bolivisión SRL }\end{array}$ \\
\hline 6 & PAT & 1998 & $\begin{array}{l}\text { Entretener } \\
\text { (generalista) }\end{array}$ & Comercializadora Multimedia del Sur SRL \\
\hline 7 & Cadena A & 2009 & $\begin{array}{l}\text { Informar y entretener } \\
\text { (generalista) }\end{array}$ & $\begin{array}{l}\text { Compañía Comercial Minera } \\
\text { Ricacruz Ltda. }\end{array}$ \\
\hline
\end{tabular}

\section{Control de los medios televisivos privados en Colombia}

Desde el inicio de la televisión nacional en 1954, de característica pública, educativa y cultural hasta el fin del gobierno del Frente Nacional (1975), se propició un modelo mixto de funcionamiento con participación externa. Desde ese año hasta 1984 se evidenció la tendencia privatizadora de la televisión nacional pública (García-Ramírez; Barbosa, 2016). La historia de la TV colombiana describe la sucesiva disolución de la televisión pública y el favorecimiento a los intereses económicos privados de las élites y conglomerados transnacionales que confunden lo público y lo privado en la circulación de contendidos (Gutiérrez, 2015).

Según Arenas (2015) el control de los medios televisivos en Colombia está en manos del duopolio mediático de las corporaciones Caracol y RCN. Entre los dos, poseen aproximadamente el $50 \%$ de la cuota de audiencia. Los colombianos por más de quince años ansían tener un tercer canal nacional que haga frente a este modelo de control, cada vez que el gobierno intenta cambiar este panorama, los dos canales se vuelven en aliados para objetar nuevas políticas de administración y de contenidos mediáticos.
El control de contenidos TV por las transnacionales provoca contaminación en la programación, plagada de: infoentretenimiento, banalidad y morbo 
El primer grupo conglomerado que maneja el canal televisivo nacional con mayor audiencia en Colombia es Caracol que pertenece al grupo Santo Domingo (propiedad de Alejandro Santo Domingo). Se fundó en 1967, inició sus emisiones como canal independiente en 1998. Su señal acapara más de 700 municipios, y su emisión internacional alcanza a más de 20 países, es operado por Valorem SA (Fecolper; Reporteros Sin Fronteras, 2015).

En la web oficial del grupo empresarial múltiple Ardila Lülle (en las áreas de bebidas, agroindustria, automotriz, deportes, medios y otros), se evidencia la posesión de operadoras de televisión como RCN Televisión, RCN Novelas, RCN Cine, WIN Sport, además de NTN24 canal latino de noticias y Mundo Fox, medio internacional de entretenimiento (figura 3).

La Autoridad Nacional de Televisión de la República de Colombia (2019) confirma la concesión de canales nacionales en sus registros. El primer canal es Caracol Televisión SA, cuyo representante legal es Jorge Del Cristo Martínez De León que opera desde Bogotá. El segundo canal registrado oficialmente es RCN Televisión SA, cuyo representante legal es Gabriel Martín Reyes Copello, que también opera desde la capital colombiana.

En Colombia existen tres conglomerados empresariales que controlan los medios nacionales, entre ellos los televisivos. Los dueños de estas estructuras mediáticas son Carlos Sarmiento Angulo, Carlos Ardila Lülle y Alejandro Santo Domingo.

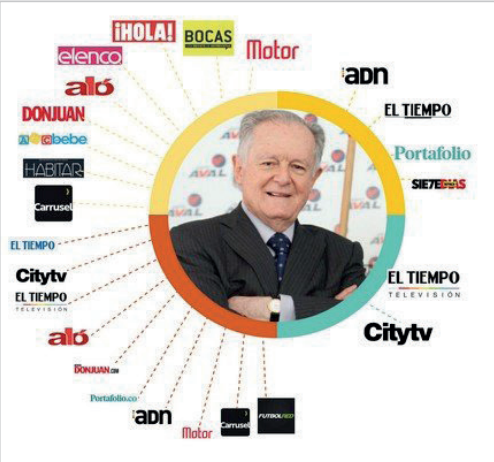

Organización Luis Carlos Sarmiento Angulo
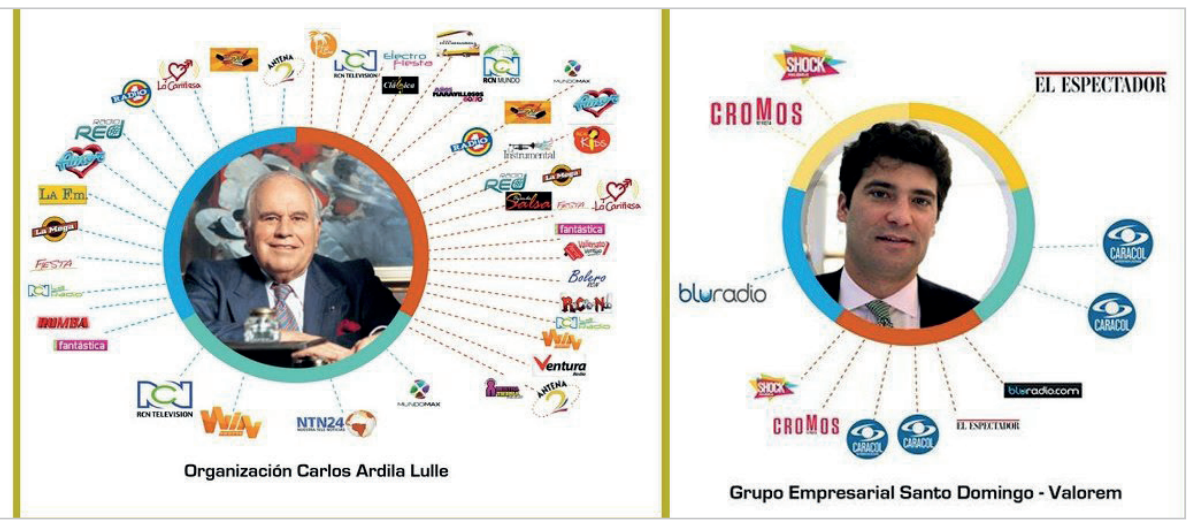

Figura 4. Dueños de los medios privados televisivos de Colombia

Fuente: Fecolper y Reporteros Sin Fronteras (2015)

http://bit.ly/2JbC2Se

La televisión privada en Colombia tuvo pasajes convergentes, entre el hecho de la expansión comercial-empresarial y el favorecimiento político en distintas épocas. Tuvieron un sistema mixto de funcionamiento entre productores privados de contenidos y administración estatal (Toussaint, 2017). Este sistema duró aproximadamente cuatro décadas, y luego los canales de empresas privadas acapararon y concentraron los medios en pocas manos. A partir de 1994 los medios mixtos se privatizaron por completo.

Tabla 3. Medios nacionales televisivos privados de Colombia

\begin{tabular}{|l|l|l|l|l|}
\hline No & \multicolumn{1}{|c|}{ Medio TV } & \multicolumn{1}{|c|}{ Inicio } & \multicolumn{1}{|c|}{ Función/programación } & \multicolumn{1}{c|}{ Control } \\
\hline 1 & Caracol Televisión & 1969 & $\begin{array}{l}\text { Informar y entretener } \\
\text { (generalista) }\end{array}$ & $\begin{array}{l}\text { Grupo Santo Domingo: propietario Alejandro Santo Domingo. } \\
\text { Operado por Valorem SA }\end{array}$ \\
\hline 2 & RCN Televisión & $1967 / 1998$ & $\begin{array}{l}\text { Informar y entretener } \\
\text { (generalista) }\end{array}$ & $\begin{array}{l}\text { Grupo Ardila Lülle: } \\
\text { propietario Carlos Ardila Lülle. } \\
\text { Operado por RCN Televisión SA }\end{array}$ \\
\hline 3 & City TV & 1999 & $\begin{array}{l}\text { Informary yentretener } \\
\text { (generalista) }\end{array}$ & $\begin{array}{l}\text { Grupo Casa Editorial El Tiempo: } \\
\text { propietario Carlos Sarmiento Angulo. } \\
\text { Operado por Casa Editorial El Tiempo }\end{array}$ \\
\hline
\end{tabular}




\section{Control de los medios televisivos privados en Chile}

La primera televisión privada se originó en la década de 1960 a través de la Compañía Nacional de Radiodifusión y Televisión que consolidó los cimientos de TV Radio Bolívar en 1961. Este medio privado fue primer canal que emitió una programación comercial (Hurtado, 1989). Durante esa década aparecieron 7 canales, y al finalizar el régimen militar de Augusto Pinochet el canal TVN -de titularidad pública- expandió las frecuencias con tendencia privada. Nació así Megavisión -en la actualidad canal 9 Mega-, y al mismo tiempo la repetidora Cajón del Maipo dio nacimiento a la red Frecuencia 4, con tendencia heredada del gobierno militar. En el gobierno democrático de Patricio Aylwin se fundaron la Red TV y Telecanal que competían insuficientemente por la audiencia en la exhibición de contenidos con a películas y series extranjeras (Riesenberg, 2007).

En base a los datos actuales de la web oficiales de los canales de cobertura nacional privada, y según a la cronología histórica de la TV abierta planteada por Ortega (2008), se visibilizan los canales que se encuentran vigentes:

- Canal 2 Telecanal nació el 16 de agosto de 1995 como Rock\&Pop, de propiedad de Jaime Cuadrado desde 2005, y recientemente de propiedad y control del grupo Albavisión.

- Canal 4 La Red inició transmisiones en 1991, también controlado actualmente por el conglomerado Albavisión del magnate mexicano Remigio Ángel González.

- Canal 5 de la Pontificia Universidad Católica de Valparaíso (PUCV), es el canal más antiguo de la República; inició sus transmisiones el 5 de octubre de 1957. Actualmente se denomina TV+ de propiedad de Media 23 SpA y PUCV regentado por Fernando Gualda.

- Canal 9 Mega, fue el primer canal privado de origen, que emite señal desde el 22 de octubre de 1990. Actualmente es propiedad de Holding Bethia y Discovery Inc. (cuyos dueños son Liliana Solari y Carlos Heller Solari).

- Canal 11 Chilevisión inició actividades el 4 de noviembre de 1960. El uso le pertenece desde 2005 a una sociedad privada dirigida por el empresario Sebastián Piñera -actual presidente de Chile-, que para estos momentos pertenece a la norteamericana Turner, casa fundadora de CNN, Cartoon Network y TNT, entre otras señales.

- Canal 13 fue creado por la Universidad Católica el año 1959. En los últimos años cambió definitivamente de dueño, privatizándose.

El panorama televisivo privado se incentivó durante la década de los noventa, especialmente con el traspaso de canales universitarios a empresarios y corporaciones. Tal es el caso de la Universidad de Chile, que pasó a constituir Chilevisión, luego el canal 13 de la Pontificia Universidad Católica de Chile a partir de noviembre del año 2017 pasó al control del Grupo Luksic (propietario Andrónico Luksic) una de las corporaciones de empresas principales de Chile (Santa-Cruz-Achurra, 2017). En la figura 5 se observa las conexiones políticas y económicas que tiene Luksic, propietario de uno de los medios de TV más grandes de Chile.

De esa historia, hoy la televisión privada goza de la comercialización de contenidos expuestos en las programaciones televisivas, que es controlado por grupos de empresarios nacionales y transnacionales, algunos de ellos con fuertes vínculos políticos.

Tabla 4. Medios nacionales televisivos privados de Chile

\begin{tabular}{|c|c|c|c|c|}
\hline No & Medio TV & Inicio & Función/programación & Control \\
\hline 1 & $T V+$ & $1957 / 2017$ & $\begin{array}{l}\text { Entretenimiento } \\
\text { (generalista) }\end{array}$ & $\begin{array}{l}\text { Media } 23 \text { SpA y PUCV } \\
\text { Gerente: Fernando Gualda Torres. } \\
\text { Operado por } T V+S p A\end{array}$ \\
\hline 2 & Canal 13 & $1959 / 2017$ & $\begin{array}{l}\text { Informar y entretener } \\
\text { (generalista) }\end{array}$ & $\begin{array}{l}\text { Grupo Luksic. } \\
\text { Propietario: Andrónico Luksic. } \\
\text { Operado por Canal } 13 \mathrm{SpA}\end{array}$ \\
\hline 3 & Chilevisión & $\begin{array}{l}1960 \\
2005 / 2018\end{array}$ & $\begin{array}{l}\text { Informar y entretener } \\
\text { (generalista) }\end{array}$ & $\begin{array}{l}\text { WarnerMedia-Grupo Turner Broadcasting System Latinoamérica. } \\
\text { Presidente: Jorge Carey } \\
\text { Vicepresidente: Gustavo Minaker }\end{array}$ \\
\hline 4 & Mega & 1990 & $\begin{array}{l}\text { Informar y entretener } \\
\text { (generalista) }\end{array}$ & $\begin{array}{l}\text { Holding Bethia y Discovery Inc. } \\
\text { Liliana Solari y Carlos Heller Solari. } \\
\text { Operado por Red Televisiva } \\
\text { Megavisión }\end{array}$ \\
\hline 5 & La red & 1991 & Entretenimiento & $\begin{array}{l}\text { Albavisión. Propietario Remigio Ángel González. } \\
\text { Red de Telecanal (Canal Dos SA) }\end{array}$ \\
\hline 6 & Telecanal & $1995 / 2005$ & Entretenimiento & $\begin{array}{l}\text { Albavisión. Propietario Remigio Ángel González. Operado por Compañía } \\
\text { Chilena de Televisión }\end{array}$ \\
\hline
\end{tabular}

La característica principal en la relación comunicación y poder en América andina es que quienes controlan el poder mediático, también controlan el poder político y económico 


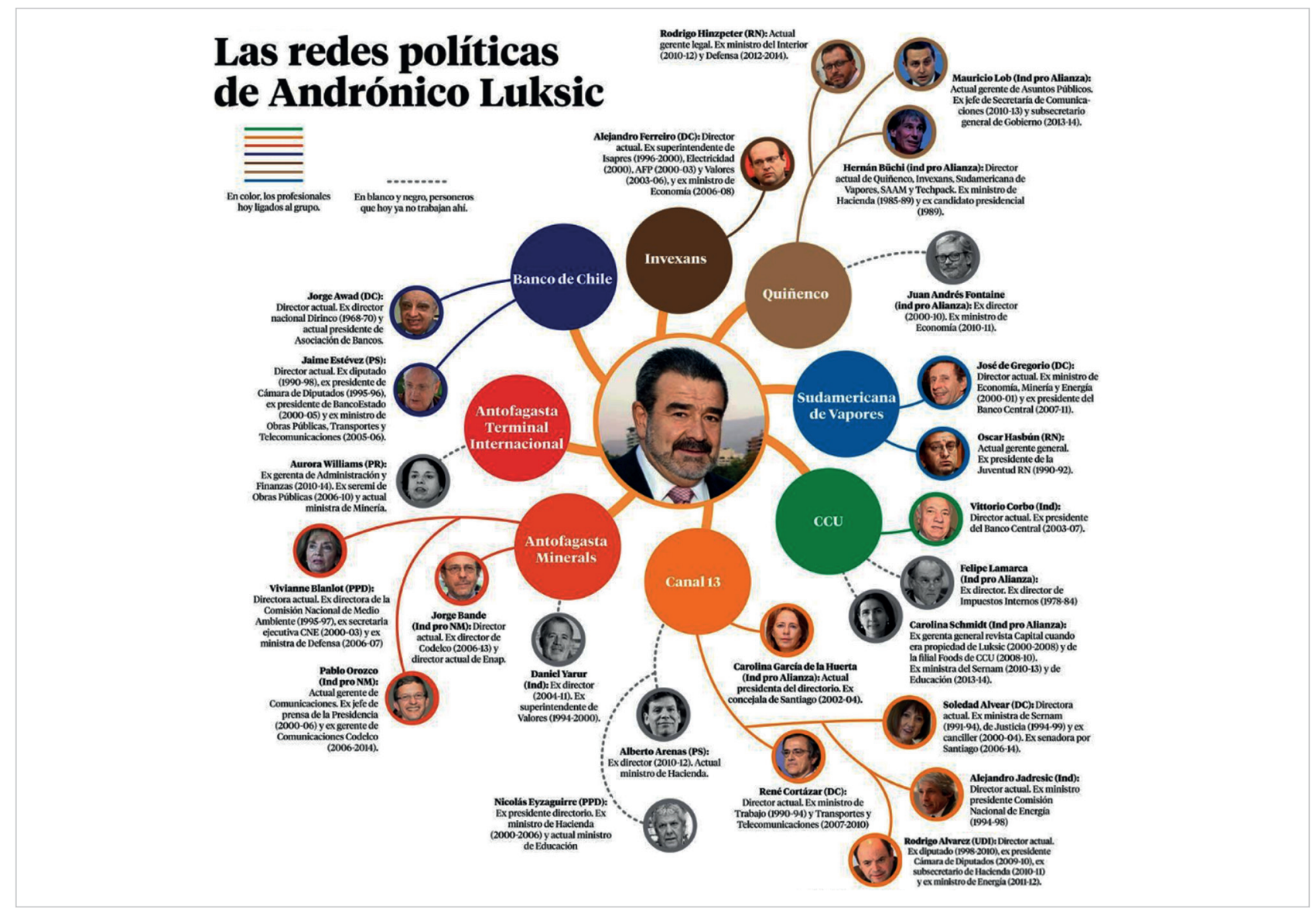

Figura 5. Andrónico Luksic, propietario de Canal 13, y sus conexiones. Fuente: $h$ ttp://bit.ly/2JoaMjM

\section{Control de los medios televisivos privados en Ecuador}

La televisión emergió por iniciativa privada de la Familia Rosenbaum en 1960 que actuaba en el canal 4 que posteriormente se denominó RTS (Red Telesistema). A partir de entonces los medios privados acapararon el sistema televisivo en Ecuador. El 1 de marzo de 1967 Xavier Alvarado Roca inició transmisiones de Ecuavisa, luego en 1974 comenzó sus transmisiones Teleamazonas, primera red a color del país y, así sucesivamente, la industria televisiva privada se expandía, gestándose: canal 2 en Guayaquil, canal 8 en Quito, Telecentro y el canal 10 (Guerrero-Córdova, 2010).

Los dueños de los medios ecuatorianos y su relación de pertenencia con Bancos no actuaban como garantes del orden democrático. Al contrario, usaban los medios para proteger sus intereses y los de sus amigos, y en ocasiones atacar a sus rivales. De algún modo los dueños de los bancos eran también dueños de los medios. Un ejemplo es Telecentro (hoy Televicentro): su dueño Fernando Aspiazu, estaba inmiscuido en el escándalo de Banco Progreso (1999-2000).

Otros casos son: Grupo Egas Grijalva, dueño del Banco Pichincha, es propietario de Teleamazonas. El grupo Eljury, dueño del Banco del Azuay, es propietario también de ETV Telerama. Ante esta situación, el sistema informativo ecuatoriano, sobre todo la televisión, perdió credibilidad durante la larga crisis. Varios propietarios huyeron del país al inicio del proceso y utilizaron sus canales de televisión para defenderse (Checa-Godoy, 2012).

Producto de esta crisis, el gobierno de Correa logró confiscar dos medios privados televisivos (Jordán; Panchana, 2010) vinculados al grupo Isaías, ex dueños del clausurado Filanbanco: Gama TV hoy Gamavisión y TC Televisión, televisoras que tenían el $38,5 \%$ de la audiencia nacional de noticias en televisión abierta. Esta situación generó reacción de la SIP (Sociedad Interamericana de Prensa), Gonzalo Marroquín su presidente refería que es una forma de someter la política editorial y la censura de prensa desde el Gobierno.

Los dueños de medios televisivos que dominaban en el Ecuador antes de la aprobación de la LOC (Ley Orgánica de Comunicación), de los cuales muchos se mantienen aún son:

- Grupo Eljuri, dueño de Telerama (12 frecuencias), Banco del Austro y otras empresas.

- Grupo Alvarado Roca, dueño de Ecuavisa (19 frecuencias), revistas: Vistazo, Hogar, Estadio, Generación, Editores Nacionales Ensa, Corporación Ecuatoriana de Negocios de Telecomunicaciones, además de acciones en Univisa, entre otros.

- Grupo Egas Grijalva, dueño de Teleamazonas, Banco Pichincha, equipo de fútbol de la Universidad Católica, y otras 12 empresas, además de acciones en el Diario Hoy, Hotel Colón, Tecnocar, entre otros 16 tipos de acciones en empresas (Estrella-Tutivén, 2018). 
Según la web oficial de la Agencia de Regulación y Control de las Telecomunicaciones (Arcotel) del Gobierno Nacional de la República del Ecuador (2019) se registran los siguientes canales de televisión de cobertura nacional privados que se encuentran vigentes:

- Red Telesistema RTS (Telecuatro Guayaquil CA);

- Teleamazonas (Teleamazonas Guayaquil SA);

- Televicentro (Organización Ecuatoriana de Televisión Ortel);

- Canal Uno (Relad SA);

- Telerama (Televisión Ecuatoriana Telerama SA);

- RTU, Radio y Televisión Unidas (concesionario y representante legal José Oswaldo Peñaherrera Muñoz;

- UCSG Televisión (Universidad Católica de Santiago de Guayaquil);

- Canela TV (Televisión Costera Costeve SA);

- Ecuavisa (Corporación Ecuatoriana de Televisión C. Ltda.); y

- Oromartv (Sistemas Globales de Comunicación HCglobal SA).

Respecto del control transnacional de medios televisivos del Ecuador, el grupo intercontinental Albavisión lidera la propiedad y manejo de medios de cobertura nacional importantes en el país, entre ellos RTS, Televicentro y LaTele. Remigio Ángel González es el dueño de la red de medios Albavisión en Ecuador (figura 6).

Los medios privados televisivos ecuatorianos de alcance nacional que difunden en distintas tecnologías, son controlados en algunos casos por bancos, empresas nacionales y transnacionales de múltiples rubros, cuyo propósito es la hegemonía mediática; les interesa la promoción de contenidos de infoentretenimiento.

\section{Albavisión en Ecuador}

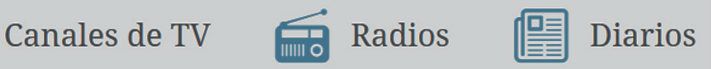
Canales de TV

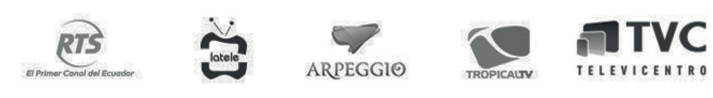

Figura 6. Dominio en la TV de Ecuador de Albavisión. Fuente: $h t t p: / / w w w . a l b a v i s i o n . t v / e c u a d o r$

Tabla 5. Medios nacionales televisivos privados de Ecuador

\begin{tabular}{|c|c|c|c|c|}
\hline No & Medio TV & Inicio & $\begin{array}{l}\text { Función/ } \\
\text { programación }\end{array}$ & Control \\
\hline 1 & $\begin{array}{l}\text { RTS-Red } \\
\text { Telesistema }\end{array}$ & 1960/1977 & $\begin{array}{l}\text { Entretenimiento e } \\
\text { información general }\end{array}$ & $\begin{array}{l}\text { Albavisión: Remigio Ángel González } \\
\text { Telecuatro Guayaquil CA }\end{array}$ \\
\hline 2 & Ecuavisa & 1967 & $\begin{array}{l}\text { Entretenimiento e } \\
\text { información general }\end{array}$ & $\begin{array}{l}\text { Grupo Alvarado Roca. Corporación Ecuatoriana de Televisión SA (Guayaquil) } \\
\text { Televisora Nacional Compañía } \\
\text { Anónima Telenacional CA (Quito) }\end{array}$ \\
\hline 3 & Teleamazonas & 1974 & $\begin{array}{l}\text { Entretenimiento e } \\
\text { información general }\end{array}$ & $\begin{array}{l}\text { Grupo Teleamazonas } \\
\text { Centro de Radio y Televisión, } \\
\text { Cratel SA (Quito) } \\
\text { Teleamazonas Guayaquil SA } \\
\text { (Guayaquil) }\end{array}$ \\
\hline 4 & Televicentro & $1984 / 2016$ & $\begin{array}{l}\text { Información y } \\
\text { Entretenimiento } \\
\text { general }\end{array}$ & $\begin{array}{l}\text { Albavisión: Remigio Ángel González } \\
\text { Operado por: Organización } \\
\text { Ecuatoriana de Televisión Ortel }\end{array}$ \\
\hline 5 & Canal Uno & 1992 & $\begin{array}{l}\text { Entretenimiento e } \\
\text { información general }\end{array}$ & $\begin{array}{l}\text { Grupo Rivas } \\
\text { Operado por: Relad } \\
\text { Canal Uno SA }\end{array}$ \\
\hline 6 & Telerama & 1993 & $\begin{array}{l}\text { Entretenimiento e } \\
\text { información general }\end{array}$ & $\begin{array}{l}\text { International Motors Company Inc. y Cardizales Oroibéricos SA } \\
\text { Operado por: Televisión } \\
\text { Ecuatoriana SA }\end{array}$ \\
\hline 7 & $\begin{array}{l}\text { RTU-Radio y Te- } \\
\text { levisión Unidas }\end{array}$ & 2005 & $\begin{array}{l}\text { Entretenimiento, } \\
\text { información y } \\
\text { cultura en general }\end{array}$ & $\begin{array}{l}\text { José Oswaldo Peñaherrera Muñoz, } \\
\text { Roberto Manciati Alarcón y César Augusto Alarcón Lombeyda }\end{array}$ \\
\hline 8 & $\begin{array}{l}\text { UCSG } \\
\text { Televisión }\end{array}$ & 2007 & $\begin{array}{l}\text { Información y } \\
\text { cultura general }\end{array}$ & Universidad Católica Santiago de Guayaquil \\
\hline 9 & Canela TV & 2010 & $\begin{array}{l}\text { Entretenimiento } \\
\text { musical }\end{array}$ & Grupo Canela \\
\hline 10 & Oromartv & 2010 & $\begin{array}{l}\text { Información y } \\
\text { entretenimiento }\end{array}$ & Sistemas Globales de Comunicación HC, Global SA \\
\hline 11 & Latele & 2011 & $\begin{array}{l}\text { Entretenimiento } \\
\text { juvenil }\end{array}$ & Albavisión: Remigio Ángel González \\
\hline
\end{tabular}




\section{Control de los medios televisivos privados en Perú}

Los medios privados desde sus inicios tuvieron una conexión familiar proveniente de los dueños de medios radiofónicos, que por tradición se hicieron cargo del control de la teledifusión. Según Acevedo (2016) el modelo peruano tiene rasgos liberales provenientes principalmente de Estados Unidos de predominio empresarial en el control con cierta regulación del Estado, además de la característica clientelar entre políticos y empresarios de los medios. Durante el segundo gobierno de Alan García e inicios del gobierno de Ollanta Umala, se favoreció a los principales grupos de TV nacionales, acentuándose la concentración de medios en grupos empresariales de élite, minimizando el acceso a decenas de pequeñas empresas.

“El hecho más reciente que reavivó el debate sobre la propiedad de los medios de comunicación en el Perú y los niveles de participación en los mercados de la prensa, la radio y la televisión [...] fue la adquisición del Grupo El Comercio [...] del 54\% de las acciones de Epensa" (Acevedo, 2016, p. 7).

América Televisión fue la primera teledifusora privada que inició su actividad en diciembre de 1958. El segundo en su aparición fue Panamericana de Televisión que inició en octubre de 1959, y recién en la década de los ochenta del siglo pasado aparecieron otras empresas. A fines del pasado siglo se crearon varios canales de TV y en los primeros años del presente siglo ya muchos inversores observaron como una oportunidad de negocio la posesión medios (Dettleff, 2012).

En Perú y otros países del continente los grupos de dominio mediático desarrollaron mercados grandes a través de la compra de mercados medianos y pequeños, con la compra de acciones parciales y en casos totales de los canales de TV. Grupos como Televisa, Azteca y Albavisión (México), Cisneros (Venezuela), adquirieron canales en Chile, Ecuador, El Salvador y Perú. Por ejemplo, América TV fue absorbida por la programación mexicana impuesta por los grupos Televisa y Albavisión que controlaban los negocios (Waisbord, 2000). Actualmente, América Televisión pertenece al grupo Plural TV, que conforman los empresarios de los diarios El Comercio con el 70\% de acciones y La República con el 30\% de acciones; además se confirma que tienen vínculos con Televisa de México (Atarama-Rojas; Castañeda-Purizaga; Londoño-Moreno, 2017).

Los principales medios televisivos privados según Castilla, Castro y Yáñez (2016) son grupos multimedia que tienen acciones en los rubros de la construcción, aerolíneas y el grupo de inversiones más importantes del Perú que tienen bajo su posesión a: Graña \& Montero, Latam Perú y Wiese. También, el magnate mexicano Remigio Ángel González (grupo Albavisión), desde Miami controla un imperio de 124 medios de comunicación en varios países de América Latina, además de un fondo de inversión que tiene acciones mineras y maneja millones de dólares de Credicorp y Sura-aseguradoras-desde un paraíso fiscal en las Islas Vírgenes Británicas y Caimán. Todos estos grupos concentran el $80 \%$ de los ingresos de la industria mediática del Perú, que constituyen el "paraíso mediático" de los dueños de grupos de medios privados en ese país.
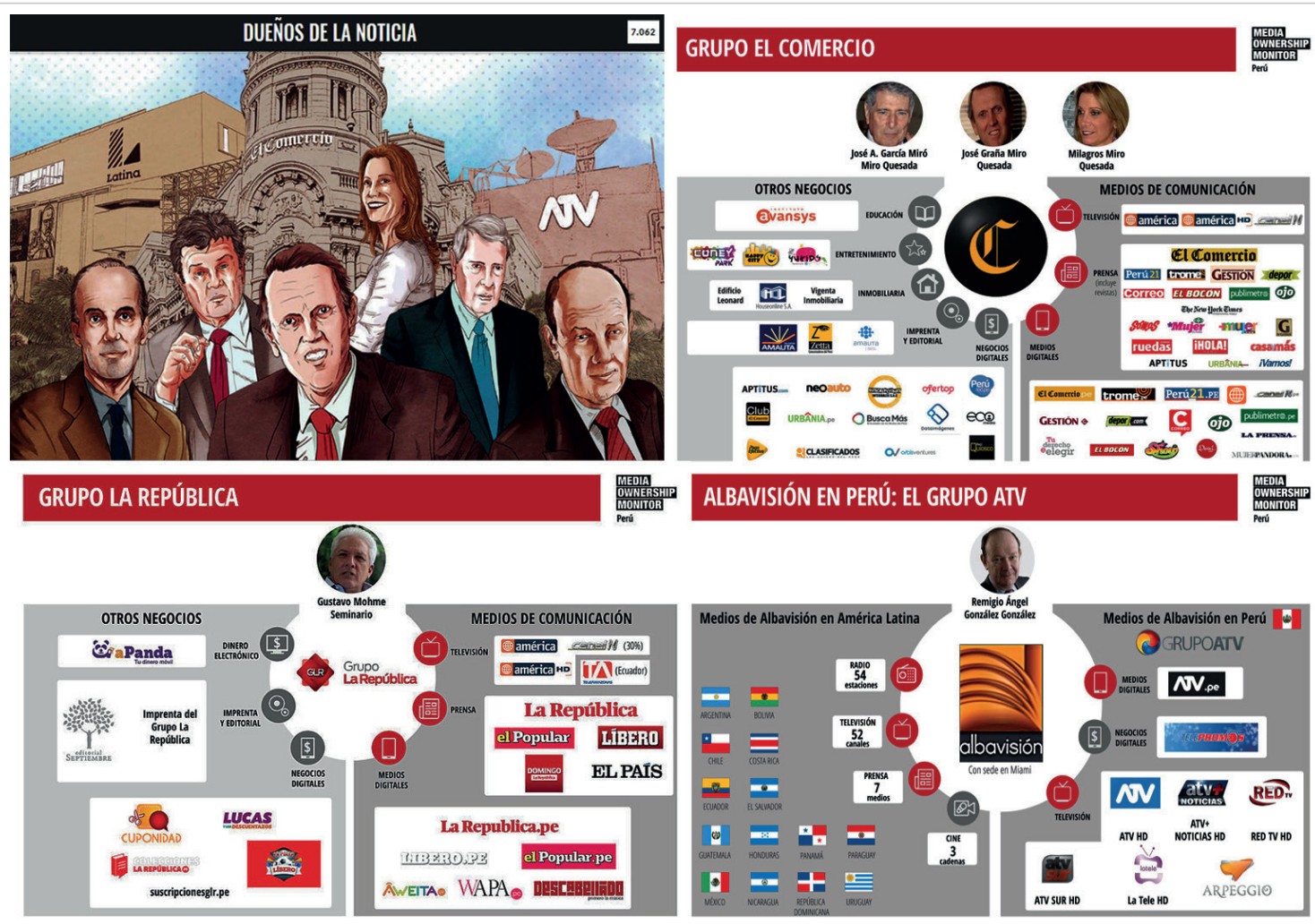

Figura 7. Dueños de los medios privados en Perú.

Fuente: Elaborado a partir de Castilla, Castro y Yáñez, (2016)

http://bit.ly/2QJvwk2 
Este panorama en la historia mediática del Perú tiene trascendencia política y comercial, de empresas que se brindan a negocios "turbios" en el escenario mediático y político del país, lo que ha marcado el desarrollo democrático eleccionario. Por ej., según Gargurevich (2015), en las operaciones mediáticas manejadas por el entonces presidente Fujimori y su asesor Vladimiro Montesinos a través de publicistas, confesó haber pagado sumas de dinero millonarias a diversos medios de comunicación televisivos influyentes a cambio del apoyo al régimen.

Los medios privados televisivos nacionales peruanos, su función y tipo de programación están bajo el control clientelar entre los conglomerados empresariales familiares nacionales e internacionales de múltiples actividades, y los políticos que se suman al negocio mediático.

Tabla 6. Medios nacionales televisivos privados del Perú

\begin{tabular}{|l|l|l|l|l|}
\hline \multicolumn{1}{|c|}{ No } & \multicolumn{1}{|c|}{ Medio TV } & \multicolumn{1}{|c|}{ Inicio } & \multicolumn{1}{|c|}{ Función/programación } & \multicolumn{1}{c|}{ Control } \\
\hline 1 & América Televisión & 1958 & Informar y entretener (generalista) & $\begin{array}{l}\text { Compañía Peruana De Radiodifusión SA, Grupo Plural TV: Familia } \\
\text { Miró Quesada (El Comercio) y familia Mohme Seminario (La } \\
\text { República) }\end{array}$ \\
\hline 2 & $\begin{array}{l}\text { Panamericana de } \\
\text { Televisión }\end{array}$ & 1959 & Informar y entretener (generalista) & Panamericana Televisión SA: Familia Schütz \\
\hline 3 & Latina Televisión & 1983 & Informar y entretener (generalista) & $\begin{array}{l}\text { Grupo Enfoca, operado por Compañía Latinoamericana de } \\
\text { Radiodifusión }\end{array}$ \\
\hline 4 & ATV & 1983 & Informar y entretener (generalista) & Albavisión: Remigio Ángel González \\
\hline 5 & Latele & 2009 & Entretenimiento infantil y juvenil & Albavisión: Remigio Ángel González \\
\hline 6 & América Next & 2017 & Informar y entretener (generalista) & Conglomerado ATVy América Televisión \\
\hline
\end{tabular}

\section{Conclusiones: los dueños de los medios en el mapa del control TV andino}

Luego de haber tratado de manera particular la pertenencia-control de los medios televisivos en cada país de la región andina, con la aplicación del método de análisis comparativo documental, se sintetiza de manera sustancial en un mapa de los principales dueños que tienen el control y poder mediático televisivo en sus manos. Existen grupos familiares, conglomerados empresariales, hasta instituciones de gobierno que controlan los medios, para sus intereses sean económicos o políticos, de pronto ambos.

La concentración mediática en pocas manos, sea económica o política, es dinámica y estable, conforma una "telaraña mediática" que es absorbida por la economía de mercado. En este complejo se manejan muchos intereses que superan lo mediático, se concreta entonces una articulación empresarial de todo tipo: grupos empresariales de medios de comunicación con otros rubros empresariales. En este panorama es difícil que la televisión privada pueda tener contenidos de calidad, ante la manipulación del mercado que no concuerda con los derechos de los ciudadanos. En ese descriterio, una forma de control de audiencias es el mito del miedo que los medios de comunicación diseminan (Reig, 2011; 2013; 2018; Reig; Mancinas-Chávez; Nogales-Bocio, 2014).

Un tipo de concentración mediática es el grupo empresarial Clarín en Argentina que tiene larga tradición, y ha constituido una red corporativa que acaparó muchas empresas del rubro (Trejo-Delarbre, 2010). Otra "telaraña mediática" es Albavisión, que controla gran cantidad de medios televisivos en el continente. El grupo Ardila Lülle en Colombia, el grupo Luksic y el grupo WarnerMedia-Turner Broadcasting en Chile, el grupo Alvarado Roca en Ecuador, grupo El Comercio en el Perú. Los grupos Monasterio, Kuljis, Akaishi Investments (Red ATB), y la comercializadora Multimedia del Sur SRL (Red PAT) en Bolivia. Estos dos últimos son considerados como empresas "paraestatales" subordinadas al gobierno (Peñaranda, 2014).

Asimismo, los canales estatales televisivos que son controlados por los gobiernos manejan contenidos para un propósito ideológico-político particular. Esta forma de proceder mediático puede ser considerado como medio ya no estatal o público, sino como medio particular de gobierno que "vende" su ideología política, característica fundamental de los gobiernos populistas en la región. En el caso de Bolivia (Herrera, 2008), los servicios de noticias del programa Bolivia Informa del canal estatal BTV (Bolivia TV) prevalece la cobertura informativa inherente al gobierno, cuya relevancia noticiosa que respalda al oficialismo proviene de las autoridades de gobierno, representantes del oficialismo, sindicatos, sectores sociales, el mismo presidente, y otros.

El acto clientelar entre empresas mediáticas y políticos es una forma de correspondencia mutua: comparten el poder económico y el gobierno de las naciones 
“La instrumentalización propagandística-gubernamental de los medios de difusión estatales ha cercenado las posibilidades de la discusión sobre el papel de estos medios [...], bajo el empeño de transformar los medios estatales (sino más bien gubernamentales) a medios públicos" (p. 233).

La presencia gubernamental-presidencial a diario está presente en la programación de BTV que incluso transmite en vivo las actividades del gobierno y del presidente Evo Morales que duran horas, e interrumpe en cualquier momento su programación.

"En tres diferentes actos, organizaciones sociales afines al MAS, proclamaron ayer al binomio Evo-Álvaro. Dos de los actos políticos fueron transmitidos de principio al final por la estatal Bolivia TV" (Layme, 2019).

Dista demasiado transformar al canal estatal en televisión pública que imparta contenidos educativos de servicio público y permita la pluralidad de criterios que no sean necesariamente afines a los intereses particulares del gobierno. Quizá una normativa consensuada con la ciudadanía representada podría transformar el panorama de los medios estatales (Campos-Freire; Soengas-Pérez; Rodríguez-Castro, 2018) hecho que permitiría frenar las interferencias o la manipulación política-gubernamental de los contenidos de los medios públicos-estatales en los países de la región.

Por el lado de los medios privados comerciales, una de las corporaciones internacionales multimedios que tiene gran presencia en el control de los medios televisivos en casi todos los países andinos de Suramérica es el consorcio Albavisión del multimillonario Remigio Ángel González. La misma web oficial de Albavisión (https://www.albavision.tv) señala que es la primera red de medios de comunicación por afiliación en América Latina. Afirman que tienen un crecimiento constante mediante la adhesión de nuevos afiliados, conecta a 114 millones de personas en 16 países. Los medios afiliados a la red Albavisión, tienen presencia en Centroamérica, Suramérica y el Caribe. En la actualidad, el número de afiliados lo conforman 45 canales de televisión, 68 emisoras de radio, 65 salas de proyección cinematográfica y 1 medio impreso. Albavisión es la red corporativa televisiva más grande del continente, que controla el poder económico y los contenidos televisivos.

Cinco de seis países de la región andina (Argentina, Bolivia, Chile, Ecuador y Perú) son del dominio televisivo del controvertido magnate mexicano Remigio Ángel González, nacido en Nuevo León en 1945, tiene también nacionalidad estadounidense,

“en 1987 estuvo preso en el Reclusorio Oriente debido a que no pagó a Gustavo Alatriste, empresario de espectáculos, por el alquiler de unas salas de cine. Al salir decidió radicar en Miami, donde opera el Grupo Albavisión" (Oalvizo, 2017, p. 1).

En el mapa de control televisivo (figura 9) se ubica a los grupos familiares, grupos empresariales nacionales, redes corporativas internacionales (transnacionales) que tienen el poder mediático, para controlar o manipular: los contenidos TV, audiencias TV (opinión pública), a los profesionales de la información, la

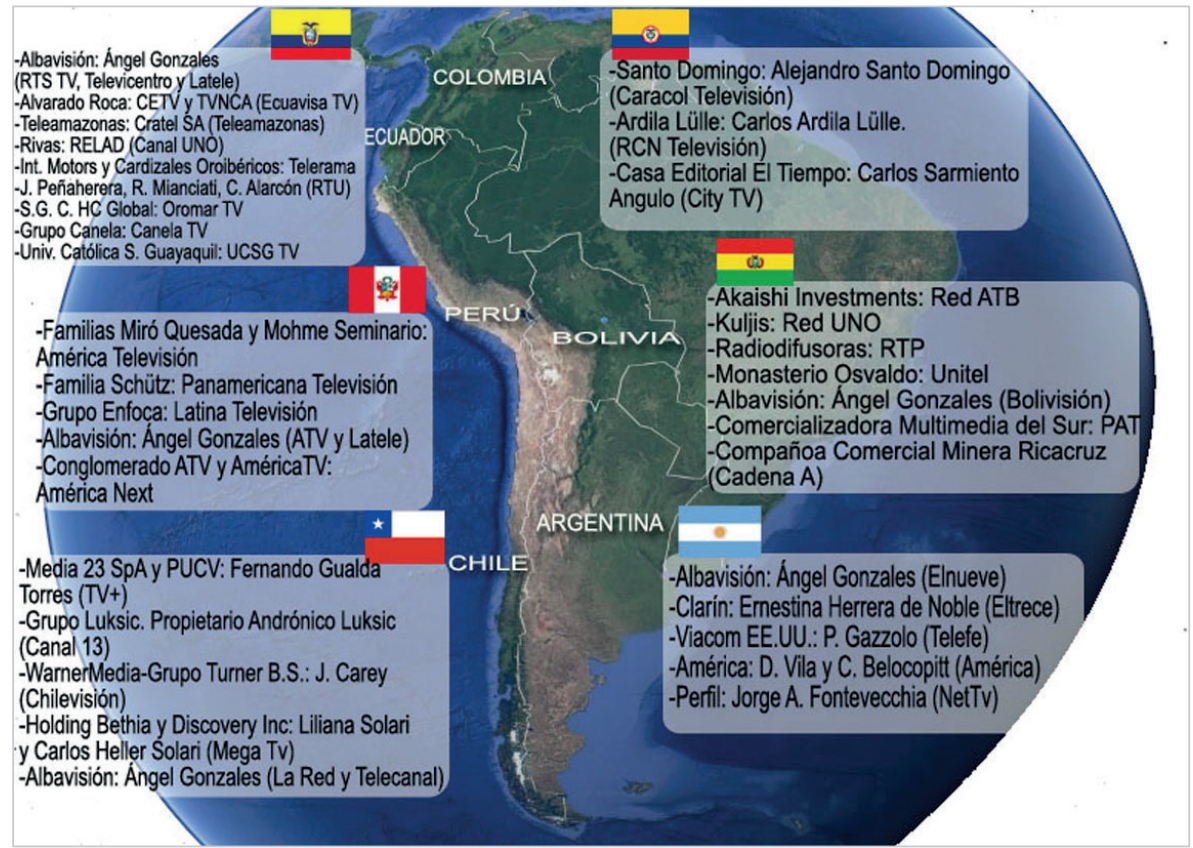

Figura 9. Mapa del control televisivo en la región andina 
economía y hasta la política gubernamental en los países de la región andina, a través de conexiones y juegos de interés para poseer y ostentar en definitiva las estructuras del poder mediático económico/político en la región andina de Sudamérica.

El panorama mediático es más que preocupante, al parecer irreversible, y se complica cada vez más por una "telaraña mediática" que continúa creciendo en su estructura de poder y ganancias en "pocas manos", además de los intereses de gobiernos por el control mediático para mimetizar la opinión pública, y retener el poder gubernamental. La única alternativa es formar profesionales y ciudadanos con pensamiento crítico, a través de la profusión del conocimiento mediático, contextualización e interpretación de la realidad social (Reig, 2015).

\section{Referencias}

Acevedo, Jorge (2016). “Monitoreo de propiedad de medios (MOM) Perú. Estudio del marco legal sobre la concentración de medios de comunicación en el Perú". Ojo público: reporteros sin fronteras, 30 pp.

http://bit.ly/2RohPfR

Ackerman, John (2018). “¿Quiénes son los dueños de medios que defienden la Revolución en Bolivia?”. Russia Today (RT). 13 diciembre.

http://bit.ly/2FDkafO

Arenas, Paula (2015). “El futuro de la televisión pública educativa y cultural. El caso de Señal Colombia”. Boletín cultural y bibliográfico, v. 49, n. 87, pp. 41-52.

http://bit.ly/2TwFI1k

Ariza, Marina; Gandini, Luciana (2012). “El análisis comparativo cualitativo como estrategia metodológica”. En: Ariza, Marina; Velasco, Laura. Métodos cualitativos y su aplicación empírica. Por los caminos de la investigación sobre la migración internacional. México: Instituto de Investigaciones Sociales y Colegio de la Frontera Norte, pp. 498-537.

http://bit.ly/2IHONJ6

Atarama-Rojas, Tomás; Castañeda-Purizaga, Lucía; Londoño-Moreno, Mateo (2017). “Televisión en el Perú: un estudio de la estrategia de difusión de contenidos de los canales de señal abierta”. Comunicación y medios, n. 35, pp. 140-155. https://doi.org/10.5354/0719-1529.2017.45196

Brandy, Gerardo (2014). "Historia de la televisión en la Argentina” [Vídeo]. Encuentro, 19 mayo. http://bit.ly/2AxQjSw

Becerra, Martín; Mastrini, Guillermo (2018). “Más dueños que nunca (variaciones en el mapa de la comunicación 20152018)". Revista Anfibia.

http://bit.ly/2CkBeUt

Campos-Freire, Francisco; Soengas-Pérez, Xosé; Rodríguez-Castro, Marta (2018). “Indicadores de evaluación de los servicios informativos de la radiotelevisión pública”. El profesional de la información, v. 27, n. 2, pp. 267-277.

https://doi.org/10.3145/epi.2018.mar.05

Carenzo, Luciano; Felipe, León (2018) “¿Quiénes son los dueños de los medios de comunicación? ¿Cuáles son las propuestas para una nueva ley de comunicación democrática?". Protectora: Portal de consumidor.

http://bit.ly/2sq/8Eh

Castilla, Óscar; Castro, Jonathan; Yáñez, Luis (2016, diciembre 1). “Dueños de la noticia”. Ojo público. http://bit.ly/2QJvwk2

Contreras-Baspineiro, Adalid (2005). De enteros y medios de comunicación: Tendencias en la oferta y el consumo mediático en Bolivia. La Paz: Cedla. Depósito Legal: 41132205

http://bit.ly/2HoLAYI

Checa-Godoy, Antonio (2012). "La banca y la propiedad de los medios: el caso de Ecuador". Revista latina de comunicación social, n. 67, pp. 6-22.

https://doi.org 10.4185/RLCS-067-950-125-147

De-Charras, Diego; Lozano, Luis (2017). "El derecho a la comunicación como una búsqueda supranacional de los pueblos". Alcance, v. 6, n. 13, pp. 3-25.

http://bit.ly/2shNRv6

Delgado, Matilde; Prado, Emili; Navarro, Celina (2017). “Ficción televisiva en Europa (EU5): origen, circulación de productos y puesta en parrilla". El profesional de la información, v. 26, n. 1, pp. 132-140.

https://doi.org/10.3145/epi.2017.ene.14

Dettleff, James (2012). "Las televisoras locales en el Perú. Una historia de su uso como herramienta política: el caso de Juliaca". Folios, revista de la Facultad de Comunicaciones, n. 27, pp. 161-184.

http://bit.ly/2FpQGSv 
El Comercio (2016). Ollanta Humala participó en lanzamiento de canal cultural Ipe, 2 julio. http://bit.ly/2VGthC1

Erbol (2014). Una investigación concluye que Vice controla 4 medios, 18 marzo.

http://bit.ly/2JhuRbg

Estrella-Tutivén, Ingrid V. (2018). La transformación de la televisión ecuatoriana a raíz de la promulgación de la ley orgánica de comunicación. Tesis doctoral. Universidad de Málaga, Málaga.

http://bit.ly/2RK3wSh

Fecolper y Reporteros Sin Fronteras (2015). “¿De quién son los medios?”. Monitoreo de la propiedad MOM. http://bit.ly/2RfHeYY

García-Ramírez, Diego; Barbosa, Marialba (2016). "Historias de la televisión en Colombia: vacíos y desafíos". Comunicación y sociedad, n. 26, pp. 95-121.

http://bit.ly/2S5q1kx

Gargurevich, Juan (2015). “Los medios masivos de información en el Perú, 1980-2012”. Conexión, n. 1, pp. 11-31.

http://bit.ly/2D3Ln9D

Gerber, Elisabet; Mastrini, Guillermo; Brant, João (2017). “El progresismo en su laberinto: grandes medios y políticas de comunicación en el Cono Sur". En: Ominami, Carlos, Claroscuro de los gobiernos progresistas. Santiago: Catalonia. ISBN 9789563245202

http://bit.ly/2sjBFJX

Guerrero-Córdova, Roberto (2010). Historia de la televisión en el Ecuador y en la ciudad de Loja. http://bit.ly/2HO2cGo

Gutiérrez, Eduardo (2015). “Entradas y claves para la historia de la televisión en Colombia”. En: Pereira, José M., Televisión y construcción de lo público, Bogotá: Pontificia Universidad Javeriana, pp. 107-114. ISBN: 9789587168884 http://bit.ly/2CXGQWI

Hernández, Roberto; Fernández, Carlos; Baptista, María-del-Pilar (2010). Metodología de la investigación. 5a ed. México: McGraw-Hill. ISBN: 9786071502919

Herrera, Karina (2008). “Cómo funciona la cobertura de Canal 7 Televisión boliviana”. En: Peñaranda, Raúl; Herrera, Karina, Los canales en cuestión: cómo trabajan Unitel y Canal 7. La Paz: FES-ILDIS, pp. 127-241.

http://bit.ly/2RXMXEC

Hurtado, María-de-la-Luz (1989). Historia de la TV en Chile (1958-1973). Santiago de Chile: Ediciones Documentas/Céneca. http://bit.ly/2ucYaBj

Jordán, Rodrigo; Panchana, Allen (2010). Los medios de comunicación en Ecuador. Quito: Universidad Los Hemisferios. http://bit.ly/2FeDfFM

Layme, Beatriz (2019). “Proclaman a Evo-Álvaro y BTV transmite los actos políticos”. Página siete, 20 febrero. http://bit.ly/2UFngUX

Martín-Barbero, Jesús (2005). “Claves de debate: televisión pública, televisión cultural: entre la renovación y la invención”. En: Rincón, Omar. Televisión Pública: del consumidor al ciudadano. Bogotá: La Crujía Ediciones, pp. 35-68. ISBN: 9586890790 http://bit.ly/2AArbum

Oalvizo (2017). "Ángel González: El magnate de la TV". Tamaulipas en la Red, 16 agosto. http://bit.ly/2HK5uOt

Ortega, Félix (2008). "La encrucijada de la televisión pública en Chile/The crossroads of public television in Chile". Cuadernos.info, n. 23, pp. 42-61.

http://bit.ly/2Jjcenl

Peñaranda, Raúl (2014). Control remoto: De cómo el gobierno de Evo Morales creó una red de medios paraestatales y un plan para acosar a la prensa independiente. La Paz-Bolivia. Depósito Legal: 4166714 http://www.raulpenaranda.net/docs/libro_Control_Remoto.pdf

Reig, Ramón (2010). La telaraña mediática. Cómo conocerla, cómo comprenderla (Colección periodística 36). Sevilla: Comunicación Social, ediciones y publicaciones. ISBN: 9788492860548

http://bit.ly/2Holzrd

Reig, Ramón (2011). Los dueños del periodismo: claves de la estructura mediática mundial y de España. Barcelona: Editorial Gedisa.

http://bit.ly/2CoZwOl 
Reig, Ramón (2013). "La correlación estructura socio-económico-mediática y mensajes: aportaciones desde el análisis de la comunicación mercantil”. Questión, n. 40, pp. 396-427.

http://bit.ly/2JdmCgy

Reig, Ramón (2015). Crisis del sistema, crisis del periodismo: contexto estructural y deseos de cambio. Barcelona: Editorial Gedisa. ISBN: 9788497849128

Reig, Ramón (2018). "La crisis de 2008: el miedo como control y negocio ideológico-mediático". Razón y palabra, v. 22 n. 1_100, pp. 151-171.

http://bit.ly/2TI7trp

Reig, Ramón; Mancinas-Chávez, Rosalba; Nogales-Bocio, Antonia I. (2014). "Un acercamiento en 2014 a la conformación de la estructura audiovisual en España y el caso de Canal Sur TV". Revista latina de comunicación social, n. 69, pp. 593-617.

https://doi.org/10.4185/RLCS-2014-1026

Riesenberg, Sergio (2007). La televisión chilena: medio siglo de historia. Chile: Universidad Uniacc. http://bit.ly/2FXqQ8K

Sanmartín, Julián; Avelino, Andrea; Reyes, Carmen; Cruz, María-José (2017). "La estructura mediática de los colectivos sociales en América Latina: los casos de Uruguay, Argentina, Ecuador y Bolivia”. Sphera publica, v. 2, n. 17, pp. 91-110. http://bit.ly/2VDOuOz

Santa-Cruz-Achurra, Eduardo (2017). "Derrotero histórico, tendencias y perspectivas de la televisión chilena". Revista comunicación y medios, n. 35, pp. 8-21.

http://bit.ly/2RAhgyS

https://doi.org/10.5354/0719-1529.2017.45906

Tonon, Graciela (2011). "La utilización del método comparativo en estudios cualitativos en ciencia política y ciencias sociales". Kairos, v. 15, n. 27, pp. 1-12.

https://dialnet.unirioja.es/descarga/articulo/3702607.pdf

Torrico-Villanueva, Erick (2011). "La reconfiguración del campo mediático boliviano desde la política (2006-2011)". Unir-Onadem, Medios a la vista 2: Análisis sobre el derecho a la información y la comunicación y el periodismo en Bolivia 2009-2011. La Paz: Quality, pp. 251-262. ISBN: 9789995482022

http://bit.ly/2HqPGzq

Toussaint, Florence (2017). "Televisión pública en América Latina: su transición a la era digital”. Revista mexicana de ciencias políticas y sociales, v. 62, n. 229, pp. 223-242.

http://bit.ly/2H1SLXg

Trejo-Delarbre, Raúl (2010). "Muchos medios en pocas manos: concentración televisiva y democracia en América Latina". Intercom-Revista brasileira de ciências da comunicação, v. 33, n. 1, pp. 17-51.

http://bit.ly/2CoEyyy

https://doi.org/10.1590/rbcc.v33i1.146

Waisbord, Silvio (2000). "Industria global, culturas y políticas locales: la internacionalización de la televisión latinoamericana". América latina hoy, n. 25, pp. 77-85.

http://www.redalyc.org/articulo.oa?id=30802509

\section{El profesional de la información Servicio de traducciones al inglés}

http://www.elprofesionaldelainformacion.com/documentos/traducciones.pdf Información: Isabel Olea epi.ioleågmail.com 